\title{
DESIGN DEVELOPMENT AND STUDY OF AN ELASTIC SECTIONAL SCREW OPERATING TOOL
}

\author{
Roman Hevko $^{a}$, Sergit Zalutskyi ${ }^{a}$, Ihor Tkachenko ${ }^{b}$, Oleg Lyashuk $^{c}$, \\ OLEKSANDRA TROKHANIAK ${ }^{d, *}$
}

${ }^{a}$ Ternopil Ivan Puluj National Technical University, Engineering Mechanics and Agricultural Machines Department, Ruska Str. 56, Ternopil, 46001 Ukraine

${ }^{b}$ Ternopil Ivan Puluj National Technical University, Manufacturing Engineering Department, Ruska Str. 56, Ternopil, 46001 Ukraine

${ }^{c}$ Ternopil Ivan Puluj National Technical University, Automobiles Department, Ruska Str. 56, Ternopil, 46001 Ukraine

${ }^{d}$ National University of Life and Environmental Sciences of Ukraine, Department of Technical Reliability, Heroiv Oborony Str. 15, Kyiv, 03040 Ukraine

* corresponding author: sashaklendii@gmail.com

ABSTRACT. The results of an elastic sectional screw operating tool development and its production technique are presented in the article under consideration. The operating tool has been made to fix the elastic sections, providing the transportation of bulk materials of agricultural production, in order to ensure their minimal damage and the process minimal power capacity. The article presents constructed regression dependencies and response surfaces for the effects of the design, kinematic and technological parameters of a sectional screw operating tool on power consumption and the damage rate of grain material in the process of its transportation. As the result of the conducted experimental research, authors came to a conclusion that the arrangement of an elastic auger without a gap between its peripheral part and the inner surface of the guiding tube significantly reduces vibrations in the process of conveying bulk material.

KEYworDS: Manufacturing method, elastic screw, process of coiling the spiral, screw making, efficiency, grain material damage.

\section{INTRODUCTION}

Transportation of bulk material by screw conveyors has a broad range of applications in different fields of production. However, conventional screw operating tools have a number of disadvantages, namely the increased material damage rate by screw conveyors due to existing gaps between the rotating part of the auger and the inner surface of the tube. This also leads to an increased power consumption of conveying the material and significant vibrational oscillations that reduce the operational life cycle of the employed mechanisms.

To increase the conveyor productivity, pneumatic devices are used, which improve material flow modes. Developments found in the works of [1 3] are dedicated to the subject of increasing the operational efficiency of pneumatic auger conveyors, and in [47], the results of a research on pneumatic conveyors with a simultaneous transportation and mixing of bulk material in the main characteristic areas routes are presented. They provide the transportation of bulk materials along technological paths of various spatial configurations employing a mechanical feed of material by a screw discharger and an additional intensification of the process with the help of pneumatic devices.
We also carried out a research analysis on improvement of operational and functional characteristics of screw and tubular conveyors and a reliable safety protection of their drive members, which are described in the works of [8, 9]. These conveyors are designed to simultaneously transport and mix bulk feed mixtures along multicurved paths with lower energy inputs of the technological process.

The works of [10, 11] are dedicated to the development of screw operating tools with an elastic surface and their theoretical and experimental research.

The works of [12 15] provide research findings on flow patterns of bulk materials depending on constructional and kinematic characteristics of screw operating tools, bunker type and solid particles, as well as frictional forces. The papers [16, 17] also presents results from an experimental screw conveyor where it is shown that the analytical predictions very closely correlate to the measured results of transportation of bulk materials.

Operating conditions, which affect the performance of screw conveyors by using a discrete element method (DEM) to simulate single-flight screw conveyors with periodic boundary conditions, are considered in [1820]. In the works of [21 23] mathematical models of the process of feeding bulk materials into bunkers of 


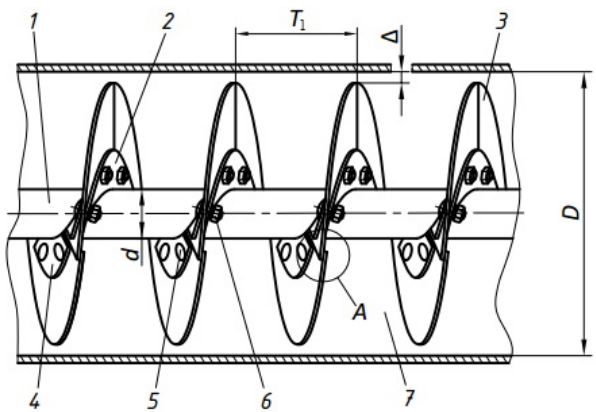

(A).

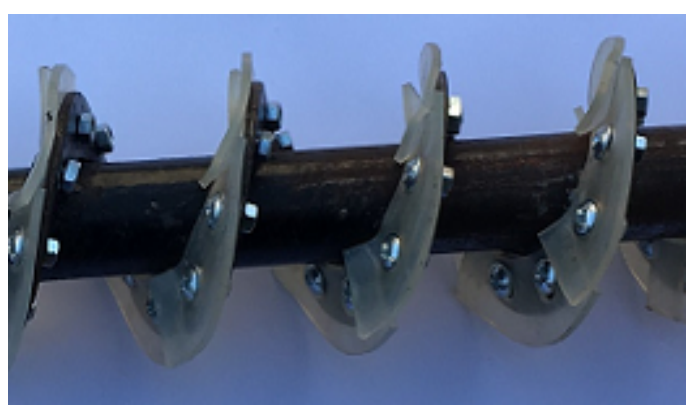

(B).

Figure 1. Design scheme (A) and general view (B) of screw operating tool with overlapping elastic sections.

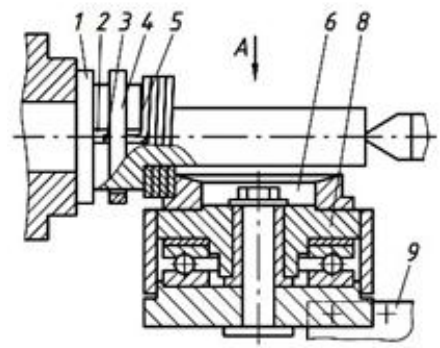

(A).

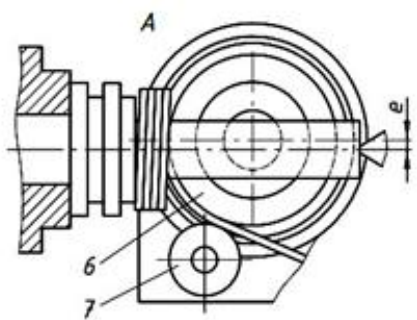

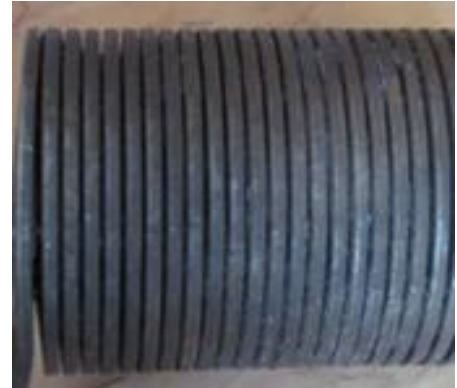

(в).

FiguRE 2. Installation diagram for coiling helices onto the stack (A) and general view of coiled helix stack (B).

screw conveyors are proposed, and operating modes of inclined screw conveyors are considered, allowing to develop their new designs with a justification of rational parameters.

The analysis of known works shows that a considerable reduction in the damage caused to agriculturallyproduced materials can be achieved by employing elastic surfaces, which are attached to the screw blade. Thereby, it is efficient to develop new designs of elastic screw operating tools and determine their optimal structural and kinematic parameters, which will improve operational performance in the processes of bulk material transportation.

The purpose of the conducted research is to increase operational performance of elastic conveyor screw operating tools by developing new designs and determining their rational parameters, as well as an application of the proposed manufacturing method.

The novelty of this work is to determine the influence of constructional and kinematic parameters of an elastic screw operating tool on the damage rate of grain material, conveyor output and the energy consumption of the transportation.

\section{MATERIAL AND METHODS}

According to the main objectives, a constructional design of an elastic sectional screw operating tool and its manufacturing method have been developed. An experimental installation has been designed to determine the productivity of an auger conveyor as well as to establish the influence of technological and kinematic parameters of a screw conveyor with hard and elastic operating surfaces on the grain degradation rate. A statistical processing of experimental research findings has been performed in order to construct, and thereafter conduct the analysis of regression equations.

To meet the objectives, an elastic sectional screw operating tool has been designed [24].

The design scheme and general view of the sectional screw operating tool with overlapping adjacent elastic sections are shown on Figure 1. It consists of the central shaft 1 (diameter $\varnothing 38$ ) with spiral body 2 , which is made of material S12 to which elastic sections 3 are attached with the help of sectional screw plates 4 , bolted joints with semi-circular heads 5 and nuts 6 .

During the transportation of the material in tubular casing 7, when the grain is stuck between the stationary casing's surface and rotating sectional elastic screw's surface, sections bend to avoid any grain damage.

The manufacturing method of the elastic sectional screw operating tool is as follows: the ribbon is coiled onto the screw stack, without performing a pitch calibration. Different types of coiling methods may be applied [25]. The process of coiling the helices out of ribbons with their continuous escape from the framework differs in the fact that acting forces, which capture and carry the ribbons, are frictional forces (Figure 2).

For the coiling, we used installation (Figure 2, which was mounted onto the metalworking lathe. The installation is made in the form of a step-like cylindrical mandrel 1, which, in its wider part, has an axial 


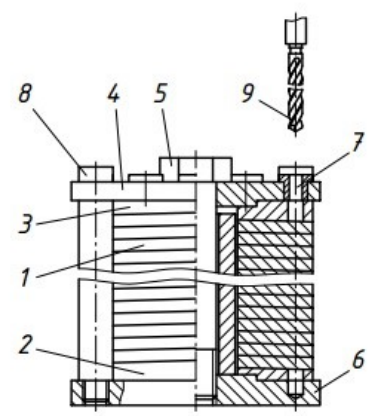

(A).

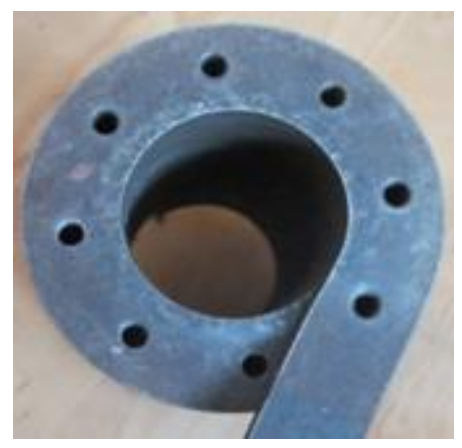

(B).

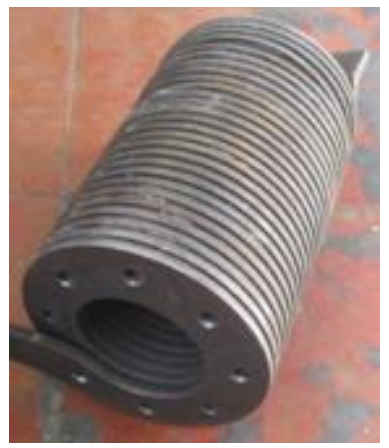

(C).

Figure 3. Fixture for drilling the screw stack (A) and its general view (B, C).

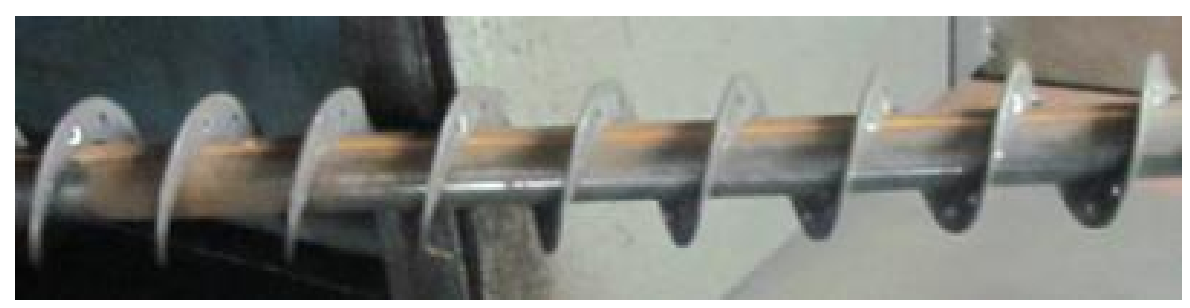

FIgURE 4. Attaching the calibrated screw onto the tubular base.

slot 2. Ribbon's bent end 3 is inserted into the slot and is fixed with bushing 4 . At the end of the mandrel, there is a single helical coil 5 with a pitch that equals to the helix width.

Clamping 6 and guide 7 rollers, with the possibility of free rotation, are mounted on the saddle, perpendicularly to the axis of the mandrel. The clamping roller has a step-like design, its cylindrical surface presses the ribbon to the bushing end 5 , and the wider part of the roller comes to contact with the ribbon rib that is being coiled. The roller is rigidly mounted on the body frame 8 , attached on the axle with the help of bushing and is set onto the saddle by means of the thrust bearing. To improve the operating conditions, the axle of thrust bearing is displaced relatively to the mandrel within the e value, sideways to the feed of the ribbon.

The installation operates the following way: the end of the ribbon, which is bent at an angle of $90^{\circ}$, is attached into the mandrel's axial slot 2 and fixed with the bushing. The pressing roller 6 is approached to the ribbon in such a manner that the roller's narrower cylindrical side presses the ribbon to the mandrel's end, and the roller's wider end surface presses down the ribbon along its rib. In this case, the end surface should be positioned from the mandrel at a distance that corresponds to the ribbon's width in the screw stack. The loose ribbon's end is bent along the surface of the pressing roller and is inserted into the gap formed by smaller sides of the pressing 6 and guiding 7 rollers. After the mandrel is set in rotation, the ribbon, under the action of the end surface of the pressing roller, is coiled onto the mandrel's smaller part. The feeding of the ribbon towards its bent side is performed by working surfaces of pressing and guiding rollers. The rotation of the mandrel is synchronized with the feed mechanism 9 , which has a pressing roller mounted on it. The feeding is determined by the maximum thickness of the inner diameter of the helix screw. After the coiling is completed, the pressing roller is drawn aside and the coiled screw stack is removed from the mandrel.

Investigations proved the possibility to coil the ribbon onto the mandrel with the ratio of ribbon width to its thickness up to $15-20$. This is due to the advantageous bend pattern and improvement of metal deformation conditions.

A diagram of mount holes and a general view of the screw stack with holes are shown in Figure 3 The screw stack 1 was attached to the fixture, which, in its lower part, has a special bushing 2 , and its end has a screw pattern with a pitch that equals the screw thickness. A similar bushing 3 is placed in the upper part of the fixture. Coils of the workpiece coming through the fixture plate 4 are maximally constricted against each other with the help of a central screw 5 , which is screwed into the fixture's body. The fixture plate 4 has through holes for attaching the fixture bushings 7 . Guiding columns 8 provide the necessary position of the plate 4 . Holes in coils are drilled by bit 9 with a spindle speed of $1000 \mathrm{rpm}$ and a feed rate that is equal to $0.2 \mathrm{~mm}$ per rotation.

The next technological step is a pitch calibration of the ribbon screw, which is rigidly jointed onto its tubular base afterwards (Figure 4).

Then, an elastic operating screw, or its sections, depending on geometric and rheological parameters of the transported material, are mechanically jointed onto the hard supporting screw (Figure 5). 


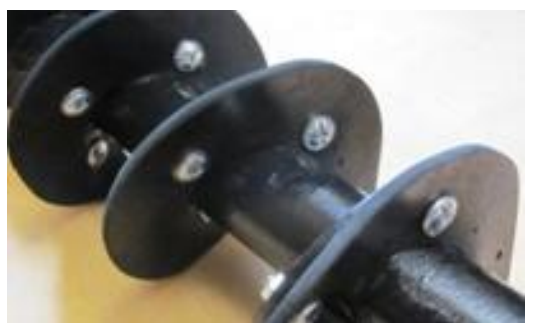

(A).

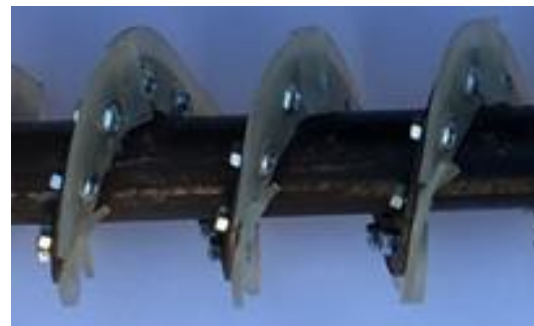

(в).

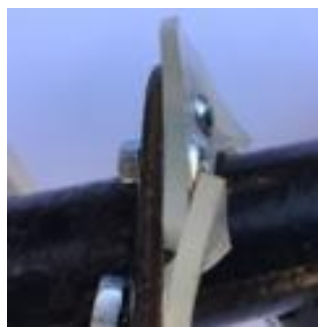

(c).

Figure 5. Solid rubber elastic screw (A) and sectional screw (B, C) attached to the base.

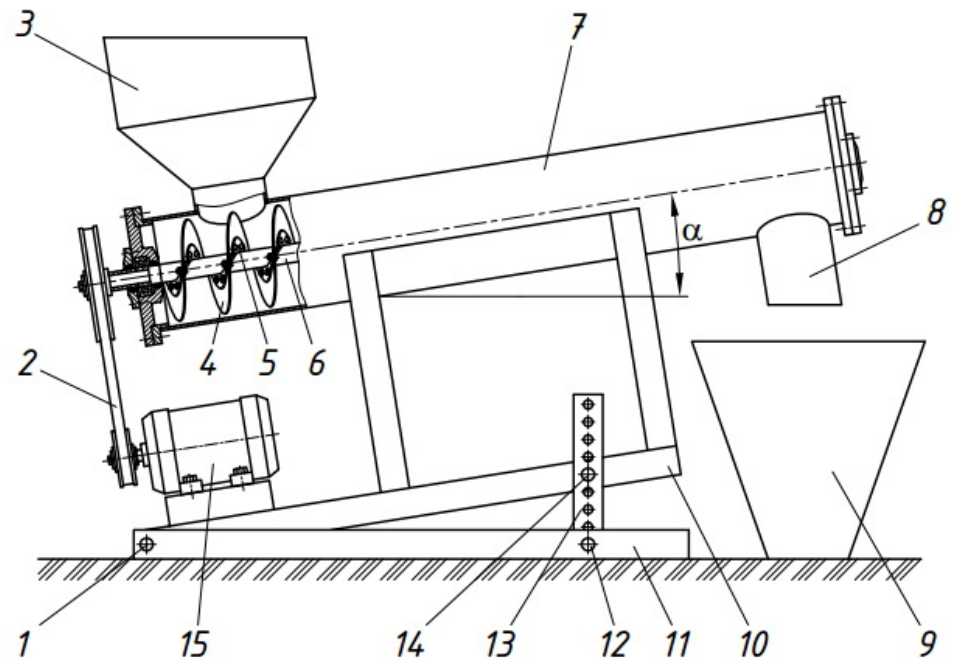

(A).

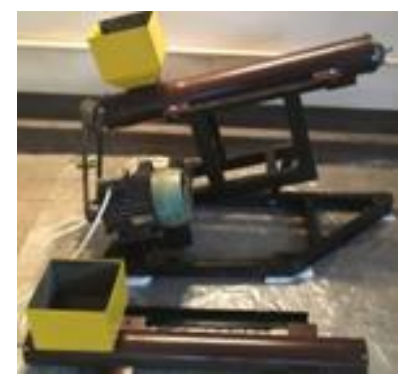

(B).

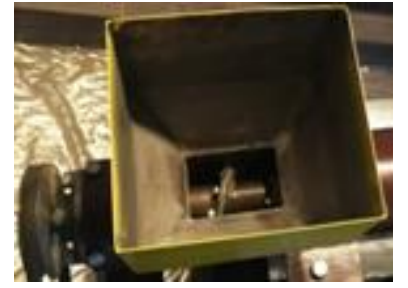

(C).

Figure 6. Design scheme (A) and general view (B, C) of experimental installation.

To evaluate the transportation productivity process and bulk material degradation rate that depends on the design, kinematic and technological characteristics of the screw conveyor with an elastic auger, an experimental installation was designed, Figure 6. It consists of a frame 11 and an auxiliary frame 10, which is attached to the frame by pivot joints 1, 12, 14 and a mounting bracket 13 with holes. An electric motor 15 with a belt driven 2 operating tool is mounted on the frame. The operating tool itself consists of a shaft 6 and a supporting ribbon screw 5 with elastic sections 4 being attached to the screw edge. The operating tool is mounted inside the guiding tube 7 , which has a bunker 3 in the feed area, a branch tube 8 in the discharge area and a bulk container 9 . The width and rigidness of the elastic sections were selected according to the stress-strain behaviour of the material being conveyed. An experimental research was conducted using polyurethane PU-60 material, the elastic sections are made with a thickness of $5 \mathrm{~mm}[26$.

Investigations on the bulk material damage during its transporting process, which depends on variations of the design and kinematic parameters of the screw operating tool, were conducted using the following method: the overall percentage of damaged grain was determined using three samples of grain before its transportation. The grain material was transported through the technological path in the screw conveyor of the experimental installation, and then, we examined the three samples of grain and determined the percentage of its damage. The discrepancy in the amount of the damaged grain material before and after the transportation indicated on its damage rate [27]. The experiment was carried out ten times, which corresponded to the general transportation distance of $10 \mathrm{~m}$.

In the process of investigation, the variation range of factors was the following: the screw operating tool rotational frequency was equal to $(n=200-500 \mathrm{rpm})$, the elevation angle $-\left(\alpha=0-40^{\circ}\right)$, and the clearance value between the auger and the casing $-(\Delta=0$ $7 \mathrm{~mm})$.

To start the $2.2 \mathrm{~kW}$ three-phase asynchronous motor and adjust its rotational speed, we used Altivar 71 frequency inverter and Power Suite v.2.5.0 software. The data obtained on motor torque and power variables were displayed in the Power Suite application window on a computer screen.

Electric motor drive power and torque values were recorded in percentage terms. The motor power was determined by multiplying its nominal output $(2.2 \mathrm{~kW})$ 


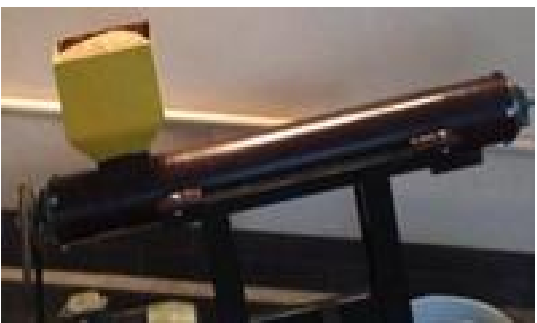

(A) . 00:00:01 sec.

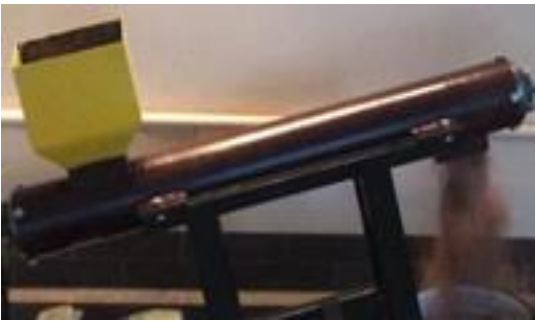

(D) . 00:00:07 sec.

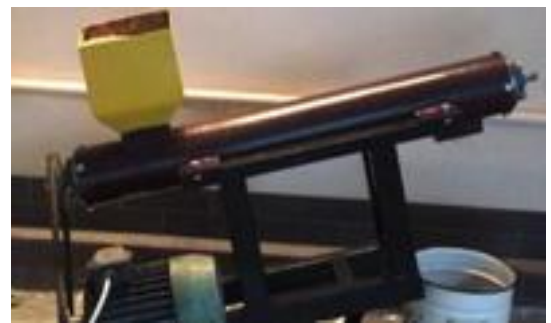

(B) . 00:00:03 sec.

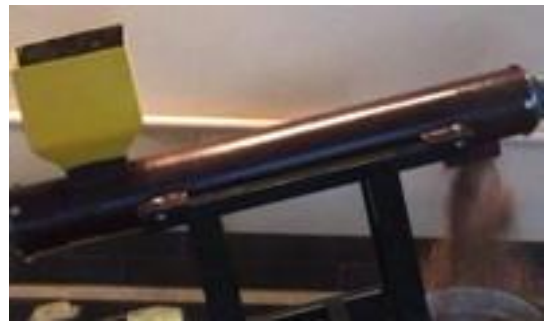

(E) . 00:00:09 sec.

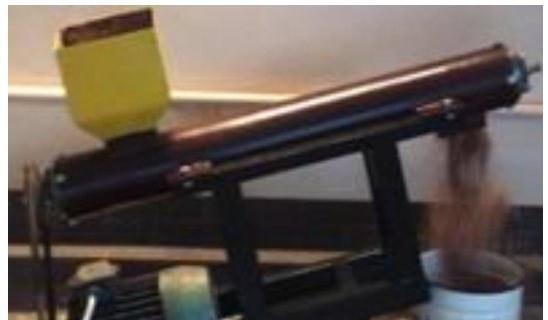

(c) . 00:00:05 sec.

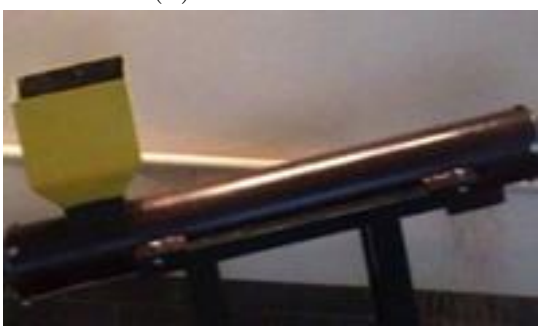

(F) . 00:00:11 sec.

FiguRE 7. Photoscript of grain material transportation process.

by a peak value (expressed in percentages) for the given operating mode.

The evaluation method of the screw conveyor production output per second consisted in selecting the grain samples within 5 seconds during the given transportation mode.

For the auger with the elastic sectional surface, the gap value $\Delta$ was equal to $0 \mathrm{~mm}$, and the same value was considered to determine the grain damage rate of winter wheat of bulk density $720 \mathrm{~kg} / \mathrm{m}^{3}$ and moisture content $\mathrm{W}=12-15 \%$.

For the rigid auger, the gap value $\Delta$ was equal to $4 \mathrm{~mm}$. Guiding jackets (tubes) with inner diameters of $D 100$ and $120 \mathrm{~mm}$ were used to determine the screw conveyor production capacity $Q$. For both variants of the screw, the screw surface pitch equals to $T_{1}=$ $70 \mathrm{~mm}$.

The photoscript for the process of conveying the grain material with $\alpha=10^{\circ}$ and $n=450 \mathrm{rpm}$ is shown in Figure 7

Having studied the photographs of the grain material transportation process, it has been determined that the peak production output of the screw conveyer, meaning its bunker being filled with grain, is between 5 and 10 sec., with $\alpha=10^{\circ}$ and $n=450 \mathrm{rpm}$. Within this timespan, the grain material was selected and weighed in order to evaluate the production output of the screw conveyor per second.

\section{Results AND Discussion}

Based on the experimental research on the evaluation of power consumption of an elastic screw conveyor during a transportation of grain material, we constructed the following regression equation

$$
\begin{array}{r}
P=0.055+0.11 \cdot 10^{-2} n-0.06 \cdot 10^{-4} \alpha \\
-0.014 \Delta+0.21 \cdot 10^{-5} n \alpha+40.84 \cdot 10^{-4} n \Delta \\
+0.75 \cdot 10^{-4} \alpha \Delta-0.33 \cdot 10^{-6} n^{2} \\
\quad+0.21 \cdot 10^{-6} \alpha^{2}-0.5 \cdot 10^{-4} \Delta^{2}
\end{array}
$$

The factorial field was determined by the following range of parameter variations $200 \leq n \leq 500$ (rpm); $0 \leq \alpha \leq 40$ (degree); $0 \leq \Delta \leq 4$ (mm).

Response surfaces, which are constructed according to regression equation 1 , are shown in Figure 8

An analysis of the response surfaces shows that the dominating factor, which influences the value $P$, is rotational speed $n$. The next impact factor is angle $\alpha$, and the least influential factor is gap value $\Delta$.

The investigation findings on the determination of productivity output $Q$ per second, during the transportation of grain material by the experimental installation with inner diameters of guiding pipes of $D=120$ and $100 \mathrm{~mm}$ at a screw rotational speed of $n=450 \mathrm{rpm}$ with a horizontal configuration of the screw operating tool, are shown of Figure 9

It was determined that the maximal screw conveyor output value was within 5 and 10 seconds after it had been set in motion and the bunker filled with grain material. Within this timespan, we selected and weighed the material.

The general tendency for the screw conveyor output $Q$ per second, depending on the inclination angle of the operating tool relative to the horizon $\alpha=0-40^{\circ}$ with $n=450 \mathrm{rpm}$, shows that value $Q$ decreases when the inclination angle of the operating tool $\alpha$ increases, whereby flow rate $Q$ considerably increases with an angle value of $\alpha=30^{\circ}$ and more.

This can be explained by the fact that at intense inclination angles of the operating tool relative to the 


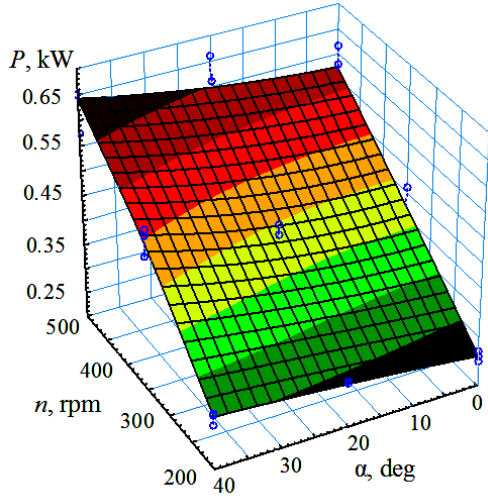

(A).

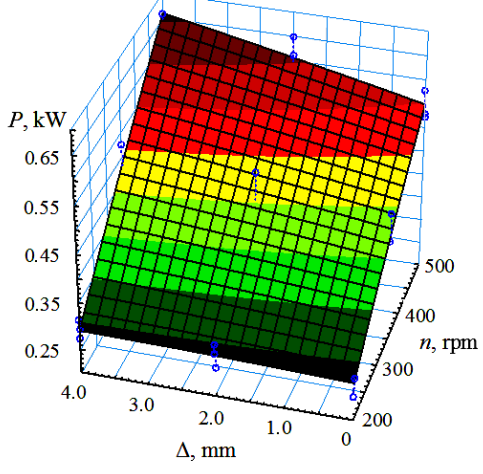

(в).

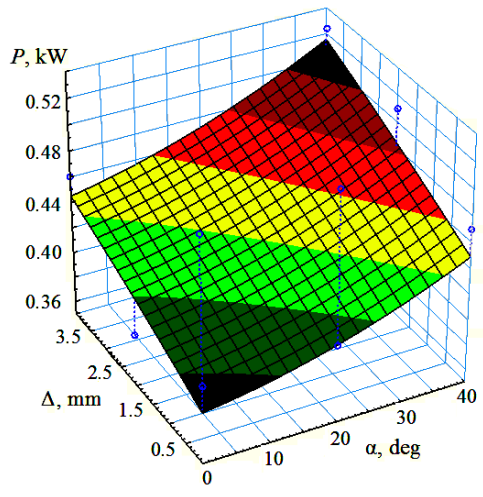

(C).

Figure 8. Response surfaces for power dependencies $P$ per conveyor drive: (A) $P=f(n, \alpha)$ with $\Delta=2 \mathrm{~mm}$; (B) $P=f(\Delta, n)$ with $\alpha=20^{\circ}$; (C) $P=f(\Delta, \alpha)$ with $n=350 \mathrm{rpm}$.

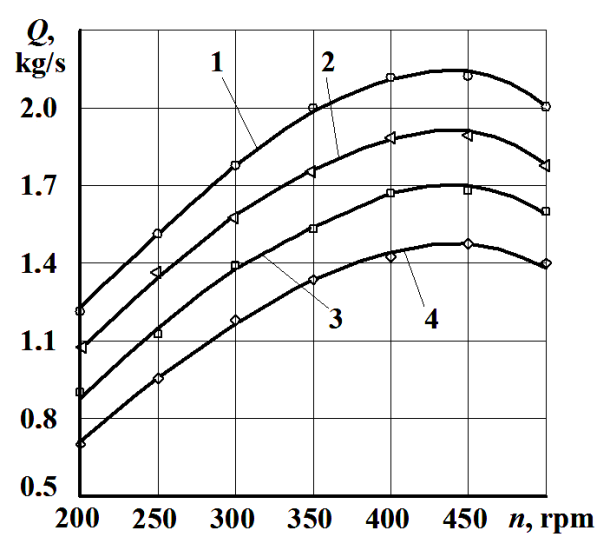

(A).

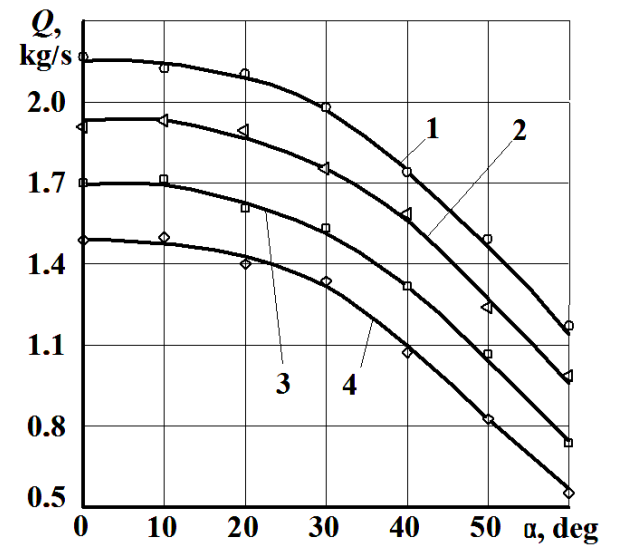

(в).

Figure 9. Characteristic curves for screw production output as per second: (A) dependency on $n=200-500 \mathrm{rpm}$ with $\alpha=0$; (B) dependency on $\alpha$ with $n=450 \mathrm{rpm} ; 1,2-D=120 \mathrm{~mm} ; 3,4-D=100 \mathrm{~mm} ; 1,3-$ screw with elastic surface (with $\Delta=0 \mathrm{~mm}$ ); 2,4 - hard screw (with $\Delta=4 \mathrm{~mm}$ ).

horizon, the feeding of grain into the guiding pipe becomes more complicated. Since the bunker is rigid and vertically fixed to the tube (Figure 6), additional frictional forces develop along the inside surface of the bunker and this slows down the feeding of material into the technological transportation zone.

The analysis of the screw conveyor production output showed that the transportation output increased 1,28-1,29 times in the case of the elastic blade augers, provided $(\Delta=0 \mathrm{~mm})$, the inside diameter of the tube was 100 to $120 \mathrm{~mm}$ and the operating tool angle inclination was within the range of $\alpha=0-40^{\circ}$, and in the case of hard screws (with $\Delta=4 \mathrm{~mm}$ ), the transportation output increased 1.28-1.33 times.

Investigations were conducted to determine the grain degradation rate caused by hard $T_{h}$ and elastic $T_{e}$ augers. The regression equation determining the dependence of the grain degradation rate on values $\alpha, n$ and $\Delta$ for the rigid auger is as follows

$$
T_{h}=0.0108+0.0046 \alpha+0.0005 n+0.053 \Delta
$$

The factorial field had the following range of parameter variations: $0^{\circ} \leq \alpha \leq 40^{\circ} ; 200 \leq n \leq 500$ (rpm); $2 \leq \Delta \leq 7(\mathrm{~mm})$.

Hard screw response surfaces $T_{h}$ depending on variations of two factors are shown in Figure 10 10a $T_{h}=f(\Delta, \alpha) ; 10 \mathrm{~b} T_{h}=f(n, \alpha) ; 10 \mathrm{c} T_{h}=f(n, \Delta)$.

The regression equation of dependencies of the grain damage on values $\alpha, n$ i $\Delta$ for the elastic screw is as follows

$$
T_{e}=0.0011+0.0012 \alpha+0.0002 n+0.051 \Delta
$$

The factorial field had the following variation range of corresponding parameters: $0^{\circ} \leq \alpha \leq 40^{\circ} ; 200 \leq$ $n \leq 500(\mathrm{rpm}) ; 0 \leq \Delta \leq 4(\mathrm{~mm})$.

Figure 11 shows the response surfaces $T_{e}$ depending on variations of two factors: $11 \mathrm{a} T_{e}=f(\Delta, \alpha) ; 11 \mathrm{~b}$ $T_{e}=f(n, \alpha) ; 11 \mathrm{c} T_{e}=f(n, \Delta)$.

The analysis of the response surfaces shows that the dominating factor that influences the value $T_{h}$ is the gap width $\Delta$. The next impact factor is angle 


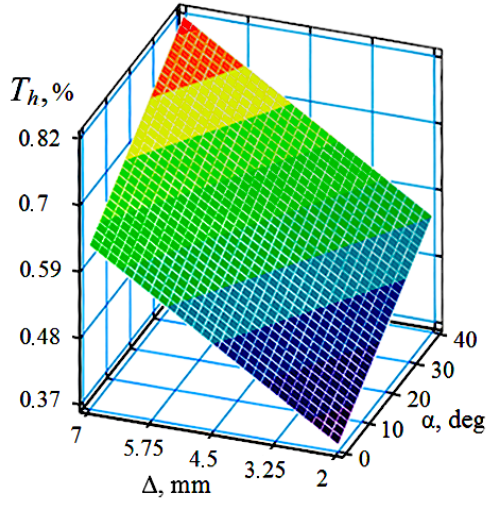

(A).

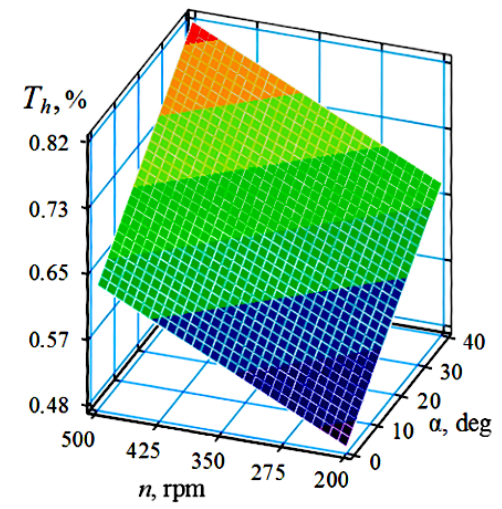

(в).

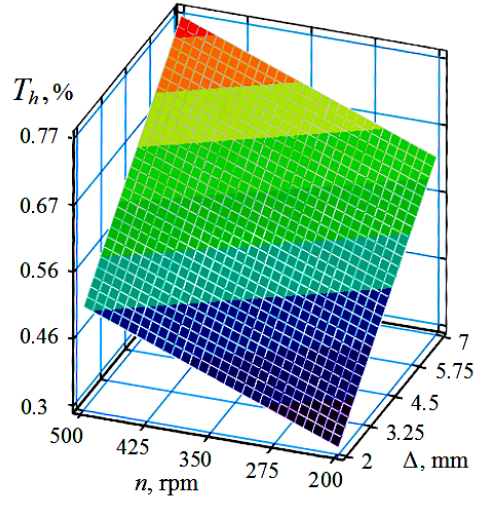

(c).

FigURE 10. Response surfaces for grain damage $T_{h}$ by hard screw depending on variations of two factors: (A) $T_{h}=f(\Delta, \alpha) ;(\mathrm{B}) T_{h}=f(n, \alpha) ;(\mathrm{C}) T_{h}=f(n, \Delta)$.

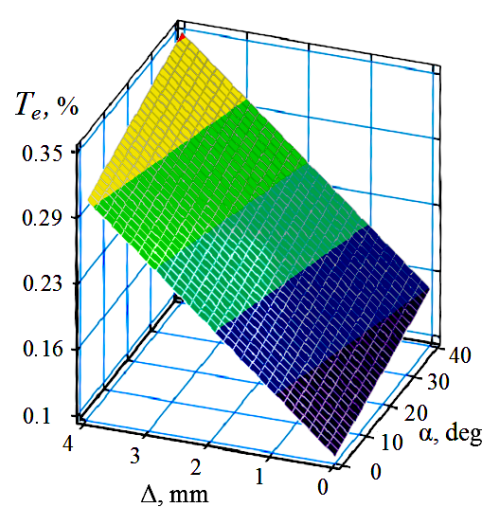

(A).

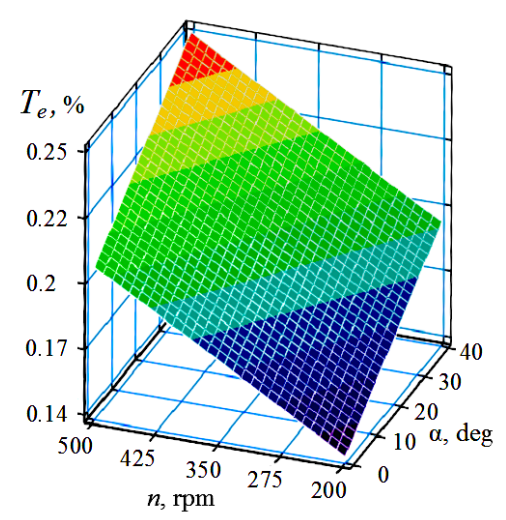

(B).

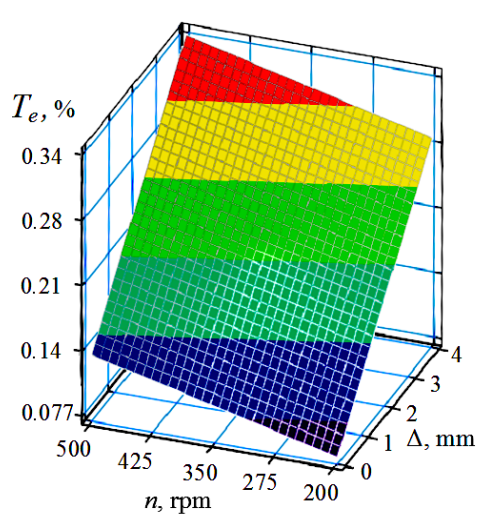

(C).

Figure 11. Response surfaces for grain damage rate $T_{e}$ by elastic auger depending on variations of two factors: (A) $T_{e}=f(\Delta, \alpha)$; (B) $T_{e}=f(n, \alpha) ;(\mathrm{C}) T_{e}=f(n, \Delta)$.

$\alpha$, and very close to it, is the rotational speed of the operating tool $n$.

The methodology of conducting the investigations on the level of the grain material damage and on the transportation-related energy consumption applying a multifactorial experiment has been suggested. The analysis of the investigation results has made it possible to assess the influence of all the above mentioned system parameters on the behaviour of the bulk material when passing the area of adjacent overlapping sections.

The presented method of making a screw operating element, which is adjusted to its fixture with elastic straps, involves a pre-coiling of a strip onto a rib with a further drilling of fixing holes in the developed conductor and a calibration of a screw base with its further fixation onto a shaft base. The ways of mounting an elastic spiral and its sections onto the base of a screw spiral rib have been suggested.

\section{Conclusions}

A completely new design of a screw operating tool with a sectional elastic surface has been developed to study the technological processes of transporting grain materials and a set of experiments has been made.

In the course of running the experimental research, the following variable values were considered: rotational speed of the operating tool $(n, \mathrm{rpm})$; its inclination angle towards the horizon ( $\alpha$, degrees); gap value between the auger and the tube $(\Delta, \mathrm{mm})$.

When determining the grain damage rate $T$, it has been established that when we used elastic sections, as compared to rigid blades, at $n=100-400 \mathrm{rpm}, T$ value decreased 1.55-3.0 times, when angle was changing within the range of $\alpha=0-40, T$ value decreased 1.634.0 times in the case of the auger with elastic blades.

Based on a multi-factor experimental research, we obtained the regression dependency on the determination of power $P$ of a screw conveyor operation. The dominating factor, which influences the power value of a screw conveyor operation is the rotational speed of the operating tool $n$. The next influential factor is the auger angle $\alpha$ towards the horizon. The gap value $\Delta$ between the elastic auger and the tube had the 
lowest impact on the power change $P$ of the conveyor drive operation.

An analysis of the screw conveyor productive output per second showed that the output of an elastic auger (provided $\Delta=0 \mathrm{~mm}$ ) with increased inside diameters of tubes from 100 to $120 \mathrm{~mm}$ at a rotational speed of the operating tool within $n=300-450 \mathrm{rpm}$ increases 1.25-1.27 times, and productivity increases $1.27-1.31$ times in the case of a rigid auger (provided $\Delta=4 \mathrm{~mm}$ ).

The general tendency of variation of the screw conveyor production output per second $Q$, depending on angles $\alpha=0-40^{\circ}$ at $n=450 \mathrm{rpm}$, shows that $Q$ value decreases, when angle $\alpha$ increases. Whereby the flow rate $Q$ significantly increases, when the angle value equals to $\alpha=30^{\circ}$ and more.

Transportation output increases 1.28-1.29 times in the case of the elastic blade augers $(\Delta=0 \mathrm{~mm})$ with an increased tube inner diameter from 100 to $120 \mathrm{~mm}$, and operating tool being inclined by $\alpha=$ $0-40^{\circ}$ towards the horizon; and in the case of the rigid augers $(\Delta=4 \mathrm{~mm})$, it increases $1.28-1.33$ times.

A completely new technique of a competitive elastic sectional screw operating tool production has been developed on the basis of the conducted set of theoretical and experimental studies. The technical innovation of the developed design is defended by the declaration of utility model patents of Ukraine 24] and the research results have been partially implemented.

\section{REFERENCES}

[1] V. M. Baranovsky, R. B. Hevko, V. O. Dzyura, et al. Justification of rational parameters of a pneumoconveyor screw feeder. INMATEH: Agricultural engineering 54(1):15-24, 2018.

[2] R. B. Hevko, O. M. Strishenets, O. L. Lyashuk, et al. Development of a pneumatic screw conveyor design and substantiation of its parameters. INMATEH: Agricultural engineering 54(1):153-160, 2018.

[3] R. B. Hevko, V. M. Baranovsky, O. L. Lyashuk, et al. The influence of bulk material flow on technical and economical performance of a screw conveyor. INMATEH: Agricultural engineering 56(3):175-184, 2018.

[4] M. Lech. Mass flow rate measurement in vertical pneumatic conveying of solid. Powder Technology 114(1-3):55-58, 2001.

https://doi.org/10.1016/S0032-5910(00)00263-1

[5] Y. Li, Y. Z. Li. New equipment for bulk cargo conveying screw-gas bulk sucking and taking equipment. In 6th International Conference on Material Handling (ICMH 2008), pp. 243-247. 2008.

[6] E. V. P. J. Manjula, W. K. Hiromi Ariyaratne, C. Ratnayake, M. C. Melaaen. A review of CFD modelling studies on pneumatic conveying and challenges in modelling offshore drill cuttings transport. Powder Technology 305:782-793, 2017. https://doi.org/10.1016/j.powtec.2016.10.026

[7] N. Tripathi, A. Sharma, S. S. Mallick, P. W. Wypych. Energy loss at bends in the pneumatic conveying of fly ash. Particuology 21:65-73, 2015.

https://doi.org/10.1016/j.partic.2014.09.003.
[8] R. B. Hevko, B. O. Yazlyuk, M. V. Liubin, et al. Feasibility study of mixture transportation and stirring process in continuous-flow conveyors. INMATEH: Agricultural engineering 51(1):49-59, 2017.

[9] R. B. Hevko, M. V. Liubin, O. A. Tokarchuk, et al. Determination of the parameters of transporting and mixing feed mixtures along the curvilinear paths of tubular conveyors. INMATEH: Agricultural Engineering 55(2):97-104, 2018.

[10] R. B. Hevko, S. Z. Zalutskyi, I. G. Tkachenko, O. M. Klendii. Development and investigation of reciprocating screw with flexible helical surface. INMATEH: Agricultural engineering 46(2):133-138, 2015.

[11] Y. Tian, P. Yuan, F. Yang, et al. Research on the principle of a new flexible screw conveyor and its power consumption. Applied Sciences 8(7):1038, 2018. https://doi.org/10.3390/app8071038.

[12] O. L. Lyashuk, O. R. Rogatynska, D. L. Serilko. Modelling of the vertical screw conveyer loading. INMATEH: Agricultural Engineering 45(1):87-94, 2015.

[13] J. W. Fernandez, P. W. Cleary, W. McBride. Effect of screw design on hopper draw dawn by a horizontal screw feeder. In Seventh International Conference on CFD in the Minerals and Process Industries CSIRO, Melbourne, Australia 9-11 December, pp. 1-6. 2011.

[14] A. W. Roberts. The influence of granular vortex motion on the volumetric performance of enclosed screw conveyors. Power technology 104(1):56-67, 1999. https://doi.org/10.1016/S0032-5910(99)00039-X

[15] X. X. Sun, W. J. Meng, Y. Yuan. Design method of a vertical screw conveyor based on Taylor-Couette-Poiseuille stable helical vortex. Advances in mechanical engineering 9(7), 2017. https://doi.org/10.1177/1687814017714984

[16] D. Schlesinger, A. Papkov. Screw conveyor calculation based on actual material properties. Powder Handling and Processing 9(4), 1997.

[17] H. Zareiforoush, M. H. Komarizadeh, M. R. Alizadeh. Effect of crop-screw parameters on rough rice grain damage in handling with a horizontal screw conveyor. Journal of Food, Agriculture and Environment 8(3-4):494-499, 2010.

[18] P. J. Owen, P. W. Cleary. Prediction of screw conveyor performance using the Discrete Element Method (DEM). Powder Technology 193(3):274-288, 2009. https://doi.org/10.1016/j.powtec.2009.03.012

[19] P. J. Owen, P. W. Cleary. Screw conveyor performance: comparison of discrete element modelling with laboratory experiments. Progress in computational fluid dynamics 10(5/6):327-333, 2010. https://doi.org/10.1504/PCFD. 2010.035366

[20] A. W. Roberts, S. Bulk. Optimizing screw conveyors. Chemical engineering 122(2):62-67, 2015.

[21] A. S. Merritt. Mechanics of tunneling machine screw conveyors: a theoretical model. Geotechnique 58(2):79-94, 2008. https://doi.org/10.1680/geot.2008.58.2.79. 
[22] O. Rogatynska, O. Liashuk, T. Peleshok, R. Liubachivskyi. Investigation of the process of loose material transportation by means of inclined screw conveyers. Bulletin of Ternopil Ivan Puluj National Technical University 79:137-143, 2015.

[23] R. M. Rohatynskyi, A. I. Diachun, A. R. Varian. Investigation of kinematics of grain material in a screw conveyor with a rotating casing. Bulletin of Kharkiv Petro Vasylenko National Technical University of Agriculture 168:24-31, 2016.
[24] R. B. Hevko, I. G. Tkachenko, S. Z. Zalutskyi, V. V. Khradovyi. Screw with sectional elastic screw surface. Patent of Ukraine No. 119856 (in Ukraine), 2017.

[25] B. M. Hevko. Manufacturing method of screw spirals. Higher School., Lviv, 1986.

[26] Poliuretan. [2018-03-25], https://electroplast.company/poliuretan

[27] M. R. Hevko. Substantiation of the parameters of sectional screw conveyers for transporting loose agriculture materials. National Technical University, Ternopil, 2013. 